\title{
ONCOPEDS: A NOVEL MOBILE APPLICATION FOR EARLY DIAGNOSIS AND REFERRALS IN CHILDHOOD CANCER
}

\author{
Liliana Vasquez ${ }^{1}$, Jacqueline Montoya ${ }^{2}$, Cecilia Ugaz $^{2}$, Ligia Rios ${ }^{3}$, Esmeralda Leon ${ }^{4}$, Ivan \\ Maza $^{5}$, ESSY MARADIEGUE ${ }^{2}$, Sharon Chavez ${ }^{2}$, Fanny Tarrillo ${ }^{3}$, Rosdali Diaz ${ }^{2}$, Ninoska $^{2}$ \\ Rojas $^{5}$, Claudia Pascual ${ }^{4}$, Mariela Tello ${ }^{6}$, Carla Moore ${ }^{6}$, Darshi Shah ${ }^{7}$, Bernardette \\ Cotrina $^{8}$, Juan Bartolo ${ }^{9}$, and Victor Palacios ${ }^{10}$ \\ ${ }^{1}$ Pan American Health Organization; Lima, Perú \\ ${ }^{2}$ Instituto Nacional de Enfermedades Neoplasicas \\ ${ }^{3}$ Rebagliati Hospital \\ ${ }^{4}$ Hospital Nacional Guillermo Almenara \\ ${ }^{5}$ Hospital Nacional Edgardo Rebagliati Martins \\ ${ }^{6}$ Instituto Nacional de Salud del Nino San Borja \\ ${ }^{7}$ Boston University \\ ${ }^{8}$ Ministry of Development and Social Inclusion \\ ${ }^{9}$ ESSALUD \\ ${ }^{10}$ Peruvian State Ministry of Health
}

June 8, 2020

\begin{abstract}
Background The diagnostic delay in children and adolescents with cancer is a public health problem in Peru leading to high rates of advanced disease and mortality. We aimed to evaluate the implementation and utility of ONCOpeds, a mobile application that provides consultations, in reducing the latency to diagnosis (LD) and referral time (RT) in children and adolescents diagnosed with cancer in Peru. Material and methods A multicenter pilot study was conducted in the region of Callao between November 2017 and April 2018. Attending primary care physicians were trained in the use of ONCOpeds in 5 educational sessions. Patients younger than 18 years living in Callao and diagnosed with cancer from all the pediatric cancer units were analyzed in two groups: referred by the mobile application or by the conventional referral. Results ONCOpeds was successfully installed in the smartphone devices of 78 attending physicians of Callao. During this period, 23 new cases of cancer in children and adolescents from Callao were collected. Ten patients were referred through the application and 13 in a conventional manner. The LD and RT were reduced in the group referred by ONCOpeds by $66 \%$ and $68 \%$, respectively; however, only the RT reached statistical significance $(\mathrm{p}=0.02)$. Conclusions The implementation of the use of ONCOpeds was feasible in this pilot study, having a potential utility in improving the diagnosis and referral in children and adolescents with suspected cancer. A larger study at the national level is required to demonstrate the effectiveness of this telemedicine tool.
\end{abstract}

\section{Hosted file}

OncoPeds Draft 250520.docx available at https://authorea.com/users/330950/articles/457948oncopeds-a-novel-mobile-application-for-early-diagnosis-and-referrals-in-childhoodcancer

\section{Hosted file}


Table 1.docx available at https://authorea.com/users/330950/articles/457948-oncopeds-anovel-mobile-application-for-early-diagnosis-and-referrals-in-childhood-cancer

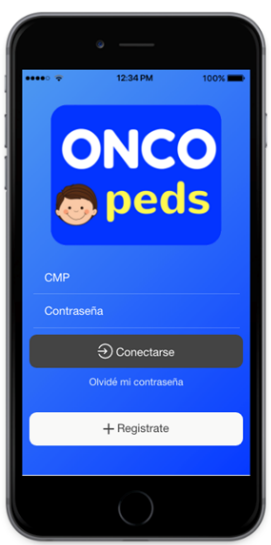

A

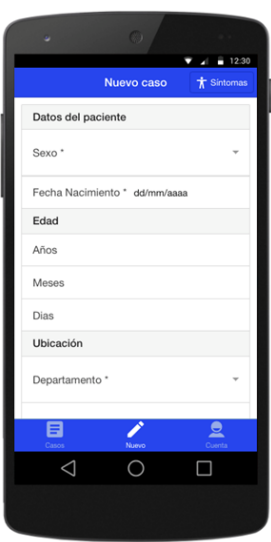

B

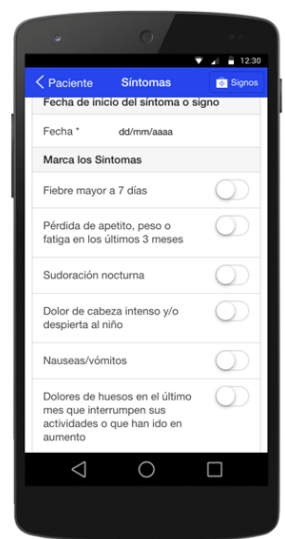

C

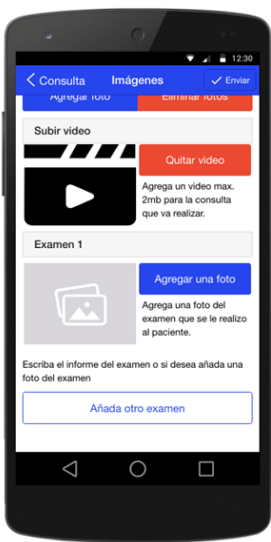

D
Data collection /

Enter case
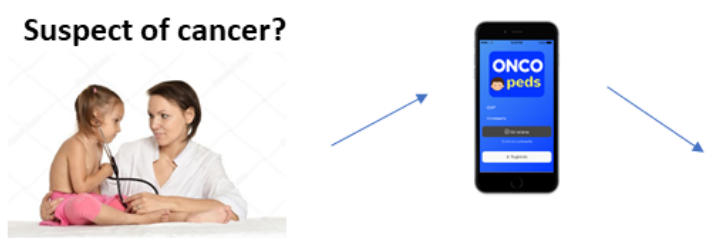

Standardized and individualized response (within 24h)

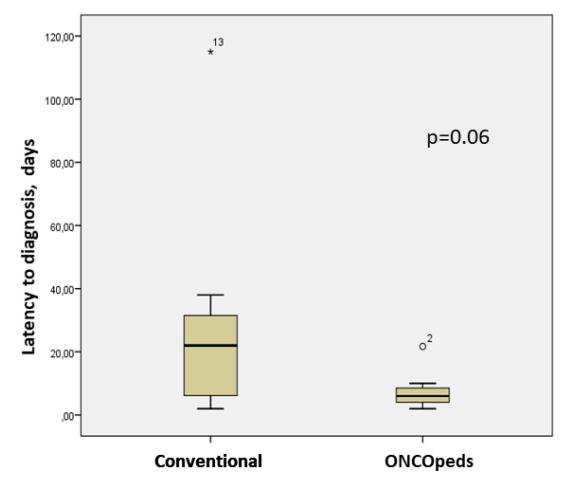

Stored into a software server in a passwordprotected cloudenvironment

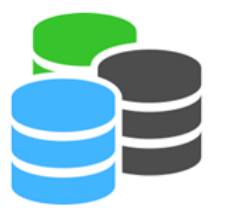

Sent to "on-call" pediatric oncologist

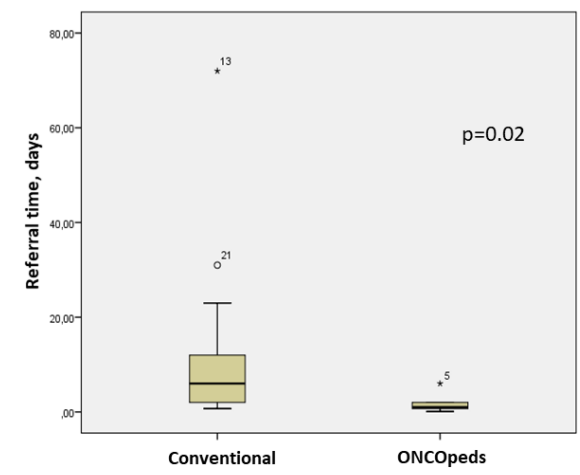

